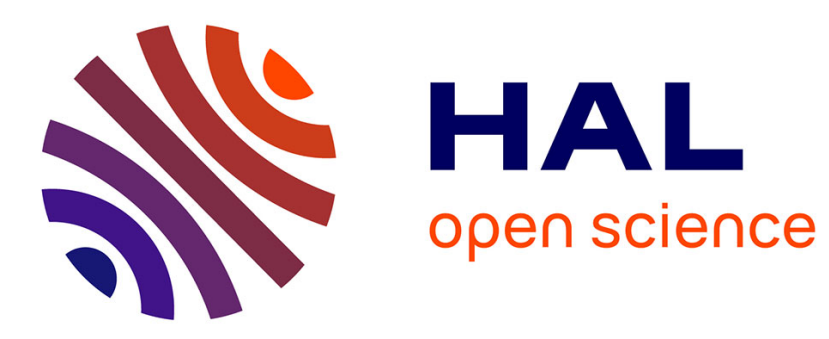

\title{
Redox (In)activations of Metalloenzymes: A Protein Film Voltammetry Approach
}

\author{
Melisa del Barrio, Vincent Fourmond
}

\section{To cite this version:}

Melisa del Barrio, Vincent Fourmond. Redox (In)activations of Metalloenzymes: A Protein Film Voltammetry Approach. ChemElectroChem, 2019, 6 (19), pp.4949-4962. 10.1002/celc.201901028 . hal-02308474

\section{HAL Id: hal-02308474 \\ https://hal.science/hal-02308474}

Submitted on 8 Oct 2019

HAL is a multi-disciplinary open access archive for the deposit and dissemination of scientific research documents, whether they are published or not. The documents may come from teaching and research institutions in France or abroad, or from public or private research centers.
L'archive ouverte pluridisciplinaire $\mathbf{H A L}$, est destinée au dépôt et à la diffusion de documents scientifiques de niveau recherche, publiés ou non, émanant des établissements d'enseignement et de recherche français ou étrangers, des laboratoires publics ou privés. 


\title{
Redox (in)activations of metalloenzymes: a protein film voltammetry approach
}

\author{
Melisa del Barrio ${ }^{\mathrm{a}}$, Vincent Fourmond ${ }^{* a}$ \\ ${ }^{a}$ CNRS, Aix-Marseille Université, BIP UMR 7281, 31 chemin J. Aiguier, F-13402 Marseille cedex 20, \\ France
}

\begin{abstract}
Redox metalloenzymes are omnipresent in living organisms where they catalyze key cellular reactions with great efficiency. These enzymes can often be reversibly placed into inactive states following changes in redox conditions. This is a hindrance for their use in biotechnological devices, and also a complication for their study via a structure/function approach, because structural data alone usually is not enough to discriminate between active and inactive states. However, these inactive states can also inform on the chemistry of the enzyme's active sites and on their catalytic cycles. A technique that has proved particularly valuable in the last decades for studying these processes is Protein Film Voltammetry (PFV), in which an enzyme is immobilized on an electrode in a configuration where direct electron transfer is possible. In this article, we review the studies of redox (in)activation processes using PFV, present the theory for a number of cases (reversible inactivations, irreversible activations), and give guidelines to obtain and intepret suitable kinetic data.
\end{abstract}

Keywords: Protein Film Voltammetry; redox inactivation; redox activation; metalloenzymes; hydrogenases; molybdenum enzymes; copper enzymes.

\section{Introduction}

Nature uses metalloenzymes for many key cellular functions, such as respiration, or carbon and nitrogen assimilation, probably because the richness of the chemistry of transition metals that these active sites are made from offers great flexibility and versatility. These metallic active sites are flexible in terms of the number and nature of the ligands and the coordination geometries. A prime example of this versatility is given by the large family of proteins hosting iron-sulfur clusters of a variety of forms [1]: while the most common ligand of the iron ions in iron-sulfur clusters are cysteins, other ligands are found [2] like histidines [3, 4], aspartate [5], arginine [6], threonine [7], water molecules [8], or even no ligand, for instance in the case of radical SAM enzymes, which harbor a vacant coordination position where the substrate binds $[9,10]$.

${ }^{*}$ To whom correspondance should be addressed. Email address: vincent.fourmond@imm.cnrs.fr, Phone: +33491164536

Preprint submitted to Elsevier 
This versatile chemistry is likely the origin of the high performances of redox metalloenzymes, but it is also at the root of a number of side phenomena, not related to catalysis, in which the active site loses a ligand, or binds an extrinsinc one, or simply rearranges, to yield a form of the active site that is not able to turn over anymore. The formation of these inactive species sometimes have a protective effect. For instance, $\mathrm{FeFe}$ hydrogenases, which reversibly oxidize $\mathrm{H}_{2}$ at a diiron active site, are very $\mathrm{O}_{2}$-sensitive, but some of them can be purified in an air-stable, inactive state[11-13] that regenerates the active enzyme upon reduction. However, in many cases, these inactive species have no reported physiological role. Perhaps they are just inherent consequences of the versatile chemistry of metallic active sites, and they never caused dysfunctions important enough to be selected against. However, the presence of inactive species has strong implications for the bioinorganic chemists that study these enzymes: inactivations may be deleterious for biotechnological applications, in which one should strive to maintain the activity of the biological catalysts as long as possible, and in as large a range of operating conditions as possible, or in the context of mechanistic studies using structural techniques such as X-ray crystallography or spectroscopic techniques, where the relevance of the information gained from the isolation and characterization of a given species changes completely depending on whether this species is part of the catalytic cycle, or just a dead-end species. This is why it is important to study and understand the conditions under which inactive species accumulate, and to elucidate their chemical nature. The most compelling reason for studying these inactive species, however, is that they can teach about the chemistry of the active sites, and can also inform on the catalytic cycle, just like the inhibitors that have been used in traditional enzymology to learn about the interaction between the enzyme and their substrates[14].

A technique that has proven valuable in the study of the formation and reactivation of metalloenzyme inactive species over the past 15 years is protein film voltammetry[1518], in which a redox enzyme is immobilized onto an electrode in a configuration that permits direct electron transfer. Enzymatic turnovers result in exchanges of electrons with the electrode, and generate an electrical current proportional to the activity, which can therefore be monitored with a great precision and time resolution. Following the evolution over time of the activity makes it possible to study (in)activation processes, and to measure their kinetics. This technique has enabled the discovery of many inactive species, probably because it allows the detection of the slow changes in activity that are the telltale sign of the formation or reactivation of inactive species, even when their amplitude is not large[19-22].

Inactivations have been triggered by the injection of an inhibitor, like carbon monoxide for hydrogenases[22], or sometimes by changes in the redox conditions. This review is dedicated to the use of PFV to study activation/inactivation processes that can be triggered by changes in the electrode potential. This makes it possible to use a number of techniques that have now been widely validated for the determination of the kinetic properties of the inactivation process - and thus to learn about its chemistry. This review is organized in terms of the complexity of the processes (and therefore of the difficulty of the study): reversible inactivations with 1 inactive species, with 2 inactive species, and irreversible activations. Each of the sections also develops the formalism necessary for the studies. We will introduce the metalloenzymes that are the subject of these inactivation processes along with the description of the results. 


\section{Glossary}

For the sake of clarity, and because some of the terms we use may be employed slightly differently by others, we have made a glossary with the definition of the terms as we use them in this article.

Activation: the formation of the active species from inactive species.

Active species: the collection of the species that are part of the catalytic cycle of an enzyme. The term "active species" therefore necessarily encompasses many distinct chemical species.

Background/capacitive current: current resulting from the variation of the electrode potential and the accumulation of ions in the vicinity of the electrode, which behaves as a capacitor. In chronoamperometry, its magnitude decreases exponentially after each step.

Film loss: the irreversible loss of enzyme from the electrode, due to desorption, but also irreversible inactivation[23].

Inactivation: the formation of inactive species

Inactive species: species that are not part of the catalytic cycle, dead-end species.

Irreversible activation: an activation is called irreversible if it was not possible to put the enzyme back in its original inactive state.

\section{Hysteresis in cyclic voltammetry reveals redox (in)activation processes}

Cyclic voltammetry, in which the electrode potential is swept up and down between two boundaries, is by far the most easy way to detect redox dependent inactivation processes, as they are visible as pronounced hysteresis. For instance, in figure 1a, which shows the cyclic voltammograms of a film of the NiFe hydrogenase from Aquifex aeolicus, (an enzyme that oxidizes $\mathrm{H}_{2}$ ), on the scan towards high potentials, at $E=0.1 \mathrm{~V}$, the $\mathrm{H}_{2}$ oxidation current is higher than at the same potential in the other direction. This indicates that the enzyme has inactivated, but that this process is reversed by taking the potential further down, since at $E=-0.2 \mathrm{~V}$, the two scans are superimposed, which indicates that the enzyme has the same activity during the forward and the backward scans. From this simple experiment, it is possible to conclude that the enzyme has inactivated in oxidizing conditions and reactivated under reducing conditions, in a process that is slow enough to be observed on the time scale of the voltammetry[24].

Such voltammograms with hysteresis were observed with many enzymes, such as other NiFe hydrogenases (figure 1b), molybdenum enzymes (figures $1 \mathrm{~d}$ and $\mathrm{g}$ ), laccases (figure 1e) and also $\mathrm{FeFe}$ hydrogenases (figure 1f).

However, if the existence of redox-dependent (in)activation processes is easily deduced from the hysteresis in cyclic voltammograms, is it seldom the best way to study the process. It is generally better to use chronoamperometry, in which the potential is varied in long steps during which the response over time is recorded, because it makes it easier to separate the effects of time and potential. The object of the following sections is to see how to use chronoamperometry (and sometimes cyclic voltammetry) to learn about the chemistry of these (in)activation processes. 

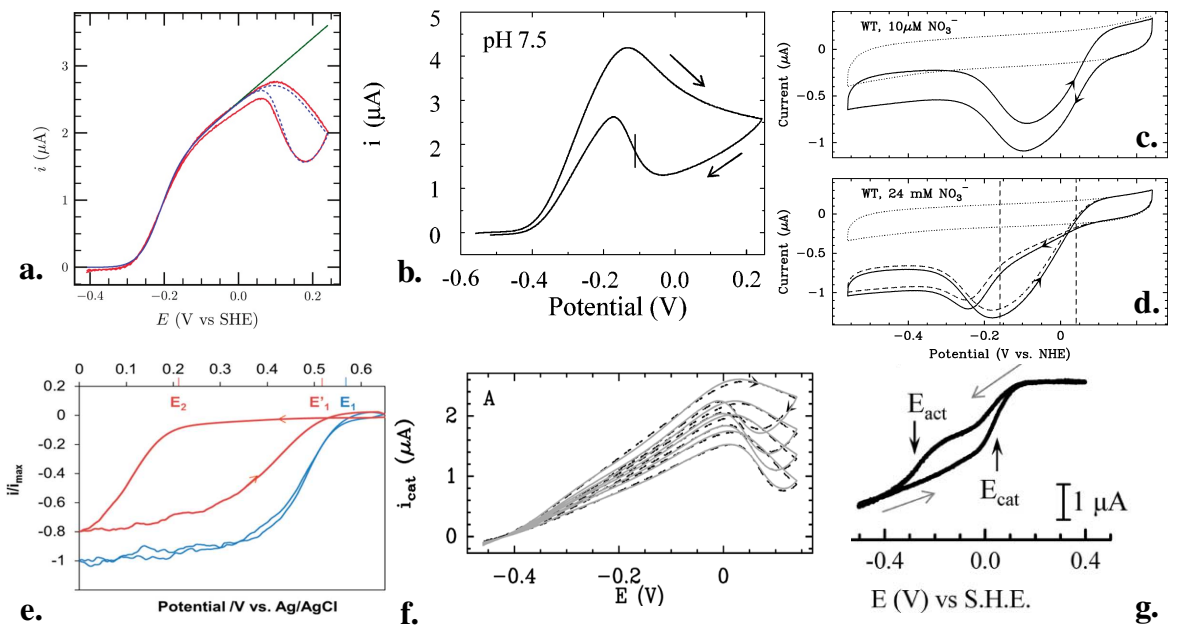

Figure 1: Cyclic voltammograms of various metalloenzymes that display hysteresis, either as a result of a reversible inactivation or an irreversible activation. For most of these processes, however, the kinetics of the (in)activation process were elucidated using chronoamperometric experiments. a. slow scans of Aquifex aeolicus $\mathrm{NiFe}$ hydrogenase (red trace), together with the computed voltammogram of the fully active enzyme (green trace) and the simulation (dotted blue line) based on the data in figure 3. Reprinted with permission from ref 24. Copyright 2010 American Chemical Society. b. slow scan of Allochromatium vinosum NiFe hydrogenase, reprinted with permission from ref 25. Copyright 2003 American Chemical Society. c,d: cyclic voltammograms of Rhodobacter sphaeroides periplasmic nitrate reductase $\mathrm{NapAB}$ at low (c) and high (d) concentrations of nitrate. Reprinted with permission from ref 26. Copyright 2010 American Chemical Society. e: voltammograms of Bacillus pumilus bilirubin oxidase in the absence (blue) or the presence (red) of chloride. Reprinted with permission from ref 27. Copyright 2017 American Chemical Society. f: cyclic voltammograms of Chlamydomonas reinhardtii $\mathrm{FeFe}$ hydrogenase at various scan rates (solid lines), together with their modelling (dotted lines). Reprinted with permission from ref 28. Copyright 2015 American Chemical Society. g: first scan of a film of Paracoccus pantotrophus NarGH showing irreversible reductive activation. Reprinted from reference 29. 


\section{Reversible inactivations with 1 inactive species}

The most commonly studied case of reversible inactivation so far, and also the simplest to study, is when the enzyme forms a unique inactive species, following scheme (1):

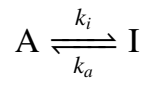

In this scheme, "A" represents the active species, "I" the inactive species, and $k_{i}$ and $k_{a}$ represent the rates of inactivation and activation respectively. Since we are dealing with redox-dependent (in)activation processes, at least one of $k_{i}$ and $k_{a}$ must be a function of the electrode potential. To learn about the chemistry of the formation of the inactive species, one needs to determine the values of $k_{i}$ and $k_{a}$ and their dependence on potential, and on other experimental parameters (such as $\mathrm{pH}, T$ and concentration of substrate).

The kinetic system of equation (1) yields the following differential equation for the evolution of the fraction of active species, $a(t)$ ( $a=1$ for a fully active enzyme):

$$
\frac{\mathrm{d} a(t)}{\mathrm{d} t}=-\left[k_{i}(E(t))+k_{a}(E(t))\right] a(t)+k_{a}(E(t))
$$

In this equation, the dependence of $k_{i}$ and $k_{a}$ on $E$, the electrode potential, has been made explicit.

The definition of "species". It is important to understand that the species of equation (1) are kinetic constructs that do not necessarily correspond to a single chemical species, but can encompass several species. "A", the active species, necessarily represents all the species of catalytic cycle. However, when considering the (in)activation process, it is possible to treat them as a single species, provided they interconvert much faster than they are converted into the inactive species "I". Similarly, "I" could be a single dead-end species, but it is more likely to represent a collection of inactive species that interconvert faster than they reactivate. The dependence of the rates on the experimental conditions (potential, $\mathrm{pH}$, etc.) can be used to learn about the chemical species that interconvert within a single "kinetic" species; $k_{a}$ inform on the inactive species, while $k_{i}$ inform on the species of the catalytic cycle.

All the (in)activation processes considered in this article are first-order in terms of the enzymatic species (i.e. they do not result from the reaction between two enzyme molecules), which leads necessarily to purely exponential relaxations, provided the rate constants do not change over time. The number of exponential phases is the number of the inactive species.

Evolution over time. If the rate constants $k_{i}$ and $k_{a}$ do not vary over time (i.e. at a constant electrode potential), scheme (1) gives a mono-exponential time evolution of the fraction of active species $a(t)$ ( $a=1$ means fully active):

$$
a(t)=\left(a_{0}-a_{\infty}\right) \exp \left(-\frac{t-t_{0}}{\tau}\right)+a_{\infty}
$$


Frame 1 Intrinsic parameter indetermination

Evolution of the current over time like that of equation (5) or (6) can both be fit with a simple mono-exponential relaxation:

$$
i(t)=i_{0}+i_{1} \times \exp \left(\frac{-t}{\tau}\right)
$$

Thus, from fitting a mono-exponential relaxation in any form, only three independent parameters can be extracted (here, $i_{0}, i_{1}$ and $\tau$ ). This shows that, in the case of equation (6), it is possible to determine $\tau, i_{a}$ and $a_{\infty}$, provided $a_{0}$ is known $\left(t_{0}\right.$ is known because it is the start time of the experiment). Conversely, it is impossible to determine the 4 parameters of equation (5), which prevents the determination of $k_{i}$ and $k_{a}$.

in which $t_{0}$ is the time at the start of the experiment, $a_{0}$ is the initial fraction of active species (at $\left.t=t_{0}\right)$, and:

$$
a_{\infty}=\frac{k_{a}}{k_{i}+k_{a}} \quad \tau=\frac{1}{k_{i}+k_{a}}
$$

This gives a time evolution of the current that can be put under the form:

$$
i(t)=\left(i_{a}-i_{i}\right)\left(a_{0}-a_{\infty}\right) \exp \left(-\frac{t-t_{0}}{\tau}\right)+\left(i_{a}-i_{i}\right) a_{\infty}+i_{i}
$$

in which $i_{a}$ is the current of the fully active form $(a=1)$ and $i_{i}$ is the current of the fully inactive form $(a=0)$. In equation (5) we made no assumption on the residual activity of the inactive form, we show below that in some cases, the residual activity can be large[30] (see section 7 below). In the following, however, we will assume that $i_{i}=0$, which is the most common case, and also because if the inactive form has a significant residual activity, intrinsic parameter indetermination (frame 1) make it impossible to determine independently $k_{i}$ and $k_{a}$. Under this assumption, the current takes the simpler form:

$$
i(t)=i_{a}\left[\left(a_{0}-a_{\infty}\right) \exp \left(-\frac{t-t_{0}}{\tau}\right)+a_{\infty}\right]
$$

It is important to note that, under given conditions $(E, \mathrm{pH}$, etc...) neither the time constant $\tau$ nor the asymptotic active fraction $a_{\infty}$ depend on the initial conditions; only the amplitude of the change inactivity does. In particular, this means that $\tau$ and $a_{\infty}$ are independent of the direction of the reaction (activation or inactivation); this is one of the diagnostics of a reversible inactivation process[26].

Equation (6) is generally not enough to reproduce experimental data, and it must be amended to take into account film loss, the slow desorption of enzyme from the electrode surface[23]. Generally, film loss takes the form of a simple exponential decrease of the total concentration of enzyme on the electrode, as in the following equation:

$$
i(t)=\left(i_{a}\left[\left(a_{0}-a_{\infty}\right) \exp \left(-\frac{t-t_{0}}{\tau}\right)+a_{\infty}\right]\right) \times \exp \left(-k_{\text {loss }} t\right)
$$




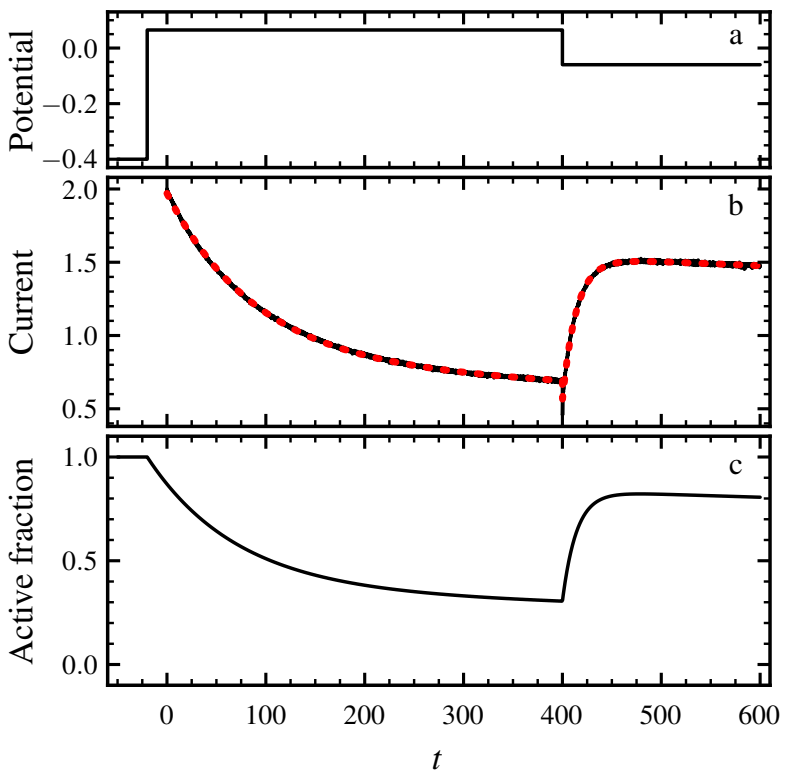

Figure 2: A simple "two step" strategy for determining the activation/inactivation rate constants for two distinct potentials $(+60$ and $-65 \mathrm{mV})$. Panel a shows the potential applied to an electrode coated with a film of Aquifex aeolicus $\mathrm{NiFe}$ hydrogenase over time. Panel $\mathrm{b}$ shows the resulting $\mathrm{H}_{2}$ oxidation current, together with fits to equation (8). Panel $\mathrm{c}$ shows the fraction of active enzyme over time, deduced from the fits. The data is replotted with permission from [24]. The original figure is copyright 2010 American Chemical Society. 
Experimental strategy. Provided $a_{0}$ is known, fitting an exponential decay to the experimental data makes it possible to determine both $a_{\infty}$ and $\tau$, and thus to determine independently $k_{i}$ and $k_{a}$, which is a prerequisite to deciphering the chemistry. Therefore, an experimental strategy to determine $k_{i}$ and $k_{a}$ for several values of potential is to measure the current during the course of a series of potential steps (figure 2), with a conditioning step known to yield a fully active enzyme. Then, on the first step, $a_{0}=1$, and for the subsequent steps, $a_{0}$ is computed from the value of $a(t)$ at the end of the previous step, assuming there is no instant (in)activation when the potential is stepped.

Simple two-steps experiments (following a reductive poise to activate the enzyme) were the first to be used[24], but more complex series of steps have also been applied, in which some of the potentials are visited both under conditions where the enzyme activates and inactivates to increase the reliability[31]. The choice of the amplitude of the potential steps is governed by two antagonistic factors: increasing the amplitude of the step generally increases the amplitude of the (in)activation, but also increases the amplitude of the capacitive current (i.e. the charging current of the electrode, whose amplitude scales more-or-less linearly with the difference in potential), which has to be subtracted from the measured current before fitting the time evolution of the current.

Dependence of the rate constants on the experimental parameters. Modelling chronoamperometric traces such as those of figure 2 yields values of $k_{i}$ and $k_{a}$ for two potentials (the two potentials after the conditioning step in figure $2 \mathrm{a}$ ). The inactivation process, and in particular the steps involved (electron transfers, (de)protonations, substrate binding) can only be understood by looking at the dependence of the rate constants on the experimental parameters: electrode potential, $\mathrm{pH}$, substrate concentration. Therefore, to understand the chemistry of an uncharacterized process, the best approach is to conduct experiments such as those of figure 2 for different values of the two potentials, to determine the dependence of the rates as a function of potential, and then conduct this experiment under different conditions ( $\mathrm{pH}$, substrate concentration). This results in plots such as those of figures 3 or 5 .

\section{1. "Anaerobic" inactivation of NiFe hydrogenases}

Perhaps the most studied reversible (oxidative) inactivation is that of the $\mathrm{NiFe}$ hydrogenases. NiFe hydrogenases catalyse the oxidation of $\mathrm{H}_{2}$ (and often the reverse reaction too) at a $\mathrm{NiFe}$ dinuclear active site. They form inactive species (named $\mathrm{NiA}$ and $\mathrm{NiB}$ ) under oxidative conditions, be it the presence of $\mathrm{O}_{2}$ [32-38], or other oxidants[35, 37-40]. Both species reactivate upon reduction, but NiA reactivates much slower than NiB.

Reversible oxidative inactivation of hydrogenases was first observed in electrochemistry with the $\mathrm{NiFe}$ hydrogenase from Allochromatium vinosum (Av)[25]. Figure $1 \mathrm{~b}$ shows a voltammogram of a film of immobilized $A v$ NiFe hydrogenase at a very slow scan rate. Upon increasing the potential, and thus the driving force for $\mathrm{H}_{2}$ oxidation, the current increases as expected, up to a certain point (around $E=-150 \mathrm{mV}$ ) where the current decreases, and keeps on decreasing even when the scan direction is reversed, down to $E=-100 \mathrm{mV}$ on the return scan where the current increases again. This pronounced hysteresis is the telltale sign of a slow oxidative reversible inactivation: the enzyme loses activity at high potential and recovers it on the return scan, upon 
reduction[25]. The potential marked by a vertical line on the return scan has been called the "switch" potential, and corresponds to the inflection point on the return scan. This potential was first interpreted as a thermodynamic parameter[25], the potential of the reduction of the $\mathrm{NiB}$ inactive species which is the one that mostly accumulates under these conditions[37], but it was later proven that it is not a thermodynamic quantity[24] (see equation (10) below).

The initial study focused on determining the rates of inactivation and reactivation under conditions in which the processes are irreversible, i.e. high potentials for the inactivation and low potentials for the reactivation, and found that, while the inactivation rate constant is independent of potential, the reactivation rate constant decreases strongly upon increasing the potential. However, it was not realized that inactivation and reactivation can occur simultaneously, and it is not until another work on a different enzyme that both $k_{i}$ and $k_{a}$ were determined simultaneously for a large range of potential.

Figure 1a shows a cyclic voltammogram of a film of Aquifex aeolicus hydrogenase immobilized on a graphite electrode, which is very similar in shape to that of $A v$ hydrogenase. This enzyme was studied using a systematic chronoamperometric two-step approach (figure 2) to determine over a large range of potential the values of $k_{i}$ and $k_{a}$, which are plotted in figure 3[24]. Indeed, similarly to what was inferred from the highpotential data of $A v$, the inactivation rate is independent of potential over the whole potential range (including the conditions in which the activation dominates), suggesting that (i) the inactivation is rate-limited by a chemical step and (ii) the concentration of the species of the catalytic cycle that inactivates does not change as a function of potential in the range explored. On the other hand, at low potentials, the activation rate constant decreases exponentially with potential, and tends to a low, constant value at high potentials. This suggest that at low potentials, the reactivation is a reduction, while at high potentials, there exists an activation pathway that is rate-limited by a chemical step. The dependence of the rate constants on potential is summarized in equations (9):

$$
k_{i}(E)=k_{i} \quad k_{a}(E)=k_{a 0} e^{-\alpha F\left(E-E^{\circ}\right) / R T}+k_{a \lim }
$$

The interpretation of the $\alpha$ coefficient is not clear. It is 1 for some enzymes, but smaller than 1 for others.

With some knowledge about the inactivation/reactivation process, it is possible to simulate the odd voltammetric traces such as those of figure 1. This was first attempted by Limoges and Savéant, with a mechanism in which the most oxidized state of the catalytic cycle slowly gave an inactive species that could be reduced back to the active form[41]. Their simulations yielded voltammograms with shapes similar to those of figure $1 \mathrm{a}, \mathrm{b}$ and $\mathrm{f}$, but no data modelling was attempted. The first experimental data modelled were those of figure 1a, using a model of the catalytic response of the fully active enzyme[42, 43] and a simple numerical integration of equation (2) using the dependence of the rates of equation (9) to determine the fraction of active enzyme. The resulting simulation, the dotted blue line on figure 1a reproduces the experimental data with great accuracy, showing that scheme (1) is enough to capture the chemistry of the process[24]. 


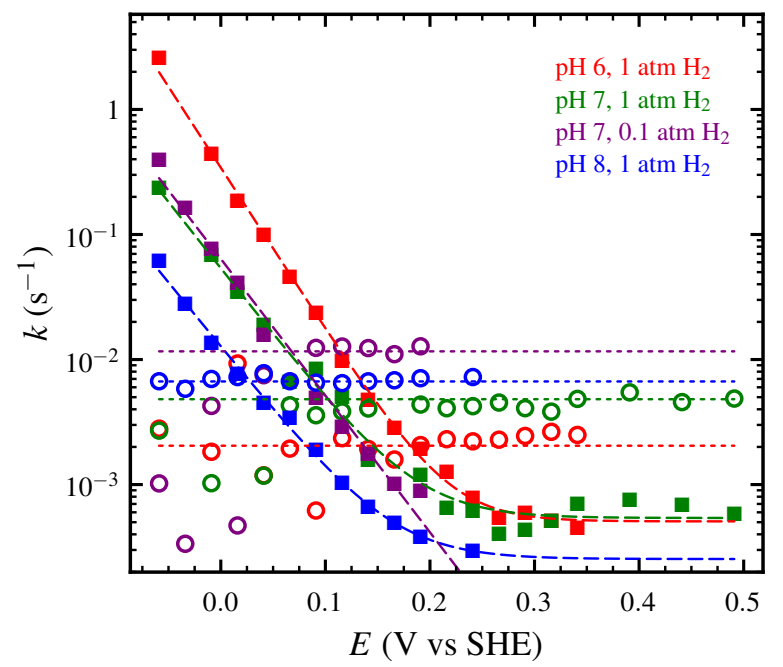

Figure 3: Activation (filled squares) and inactivation (open circles) rate constants for the anaerobic inactivation of Aquifex aeolicus hydrogenase for different $\mathrm{pH} / \mathrm{H}_{2}$ pressure, determined from chronoamperometric experiments. The dashed and dotted lines correspond to fits of equations (9). The figure is replotted with permission from [24]. Original copyright 2010 American Chemical Society.

The meaning of the switch potential. Provided the (in)activation is not at steady-state (which can only occur at very low scan rates), the position of the inflection point on the return scan of voltammograms, the "switch potential", is a kinetic parameter (i.e. not a thermodynamic parameter), corresponding to the potential at which the rate of relative increase of the activation rate constant matches the activation rate constant itself[24, 44]:

$$
k_{a}\left(E_{\mathrm{sw}}\right)=v \frac{\mathrm{d} \ln k_{a}}{\mathrm{~d} E}=\frac{F \alpha v}{R T}
$$

in which $v$ is the scan rate. This relation has been used to determine the dependence of the activation rate constant as a function of potential, under conditions where chronoamperometric experiments do not give satisfactory results because of the presence of minor, secondary, inactivations which make it impossible to reliably fit the chronoamperometric traces[45].

Modelling of the cyclic voltammograms. Half-way between the full analysis of series of potential steps to determine the values of $k_{i}$ and $k_{a}$ without making any hypothesis, and the very crude analysis of the position of the switch potential, which relies on the a priori knowledge of the dependence of the (in)activation rates on potential, it is possible to determine various kinetic parameters under the assumption of a given dependence of the rate constants on potential. This was used to quickly screen the effect of a large series of point mutations of the NiFe hydrogenase from Desulfovibrio fructosovorans: assuming a dependence on potential as in figure 3 , it was possible to fit series of voltammograms by cutting them in two: a "forward" part which informs on the rate of inactivation, and a "backward" part that informs on the rate of reactivation[44]. This 
approach is not usable for studying a new phenomenon, but it has two main advantages over chronoamperometry: (i) it is quicker, since it is only necessary to record a small number of voltammograms to obtain the information, and (ii) the main features of the voltammograms are much less sensitive to small side phenomena. In particular, chronoamperometry experiments with the mutants showed that the (in)activation process can be multiphasic[44], but the voltammograms only inform on the dominant process.

A hybrid approach was employed to characterize the anaerobic oxidative inactivation of the NiFeSe hydrogenase from Desulfovibrio vulgaris Hildenborough[45]. This enzyme forms two distinct inactive states at high potentials, which reactivate under very different redox conditions: one at high potentials and one at lower potentials. A full characterization of the lower-potential one was possible using chronoamperometric techniques such as those described above, but this strategy was not successful for the high-potential one, so the rate of reactivation was determined from the cyclic voltammograms.

Influence of the electron acceptor on the inactivation process. The nature of the electron acceptor greatly influences the anaerobic inactivation process. For instance, the mediated electrochemistry of Aquifex aeolicus hydrogenase immobilized on a butanethiolmodified gold electrode show little anaerobic inactivation at high potentials[46], while the use of quinones[47] or viologen moieties embedded in a redox hydrogel[48] completely abolish the anerobic inactivation of, respectively, Ralstonia eutropha or Desulfovibrio vulgaris Miyazaki hydrogenases. These facts underline the kinetic nature of the inactivation: changing the nature of the electron acceptor changes the rates at which electrons are abstracted from the active site, and thus impact the kinetics of the inactivation/reactivation process. As of now, no models have been proposed to better understand the effect of mediators on the inactivation processes.

\subsection{Inhibition by excess nitrate of the periplasmic nitrate reductase}

The periplasmic nitrate reductase NapAB from Rhodobacter sphaeroides $(R s)$ catalyzes the reduction of nitrate to nitrite using a molybdenum active site[49]. It belongs to the large "Mo-bis PGD" family of enzymes[50-52]. Steady-state voltammograms of $R s \mathrm{NapAB}$ in the presence of nitrate show a peculiar shape with a maximum of activity for intermediate regions of potential (figure 1c), whose occurrence has been rationalized in terms of the difference of the rates of binding of nitrate to the various redox states of the active site $[53,54]$. What concerns this review is that, under conditions of low $\mathrm{pH}$ and high substrate concentration, cyclic voltammograms of films of NapAB also show a very spectacular hysteresis (figure 1d) indicative of a reversible oxidative inactivation.

Chronoamperometry experiments in which a film of NapAB is submitted to increasing concentrations of nitrate (figure 4) have shown that, if the enzyme follows standard Michaelis-Menten behaviour at low potentials, the enzyme is slowly inhibited by excess nitrate at intermediate potentials[26], and this is what causes the pronounced hysteresis of figure 1d; this inhibition by excess nitrate at high potentials was confirmed in solution using high potential electron donors[26]. Using steps techniques similar to 


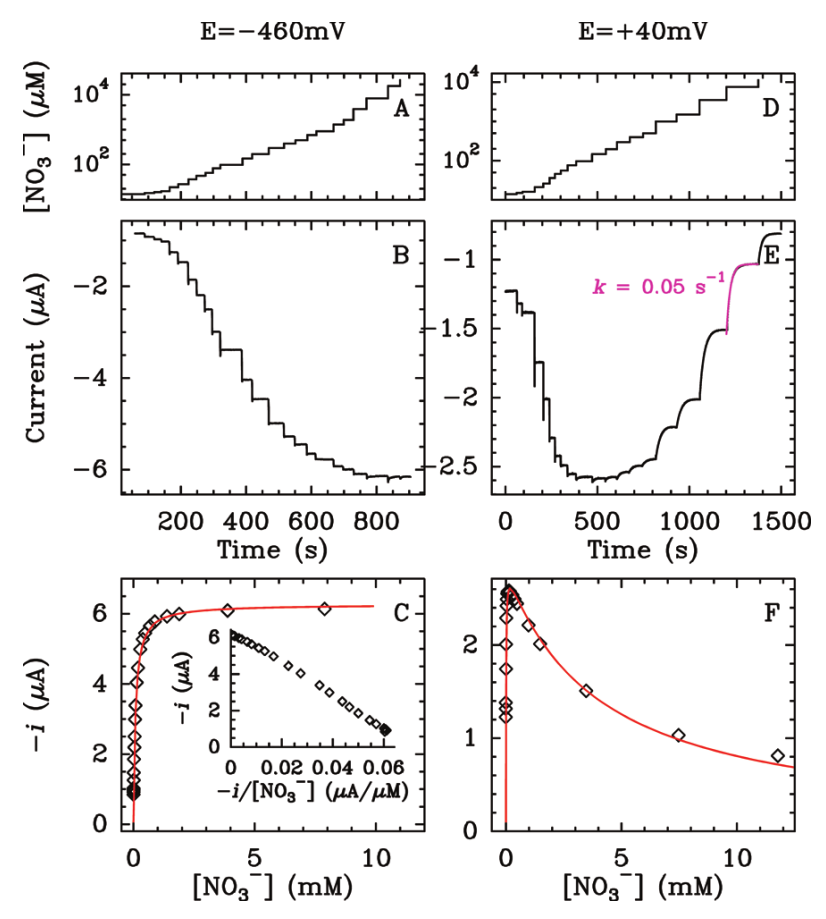

Figure 4: Chronoampetric experiments to determine the dependence of the activity of the periplasmic nitrate reductase NapAB from Rhodobacter sphaeroides on the nitrate concentration for two different potentials. The concentration of nitrate is varied stepwise by additions of concentrated aliquots (the evolution of the concentration over time is shown in panels A and D). The response in current of a film of NapAB is shown as a function of time in panels $\mathrm{B}$ and $\mathrm{E}$, and the information from all the panels are combined to show the dependence of the current as a function of the nitrate concentration for the two potentials (panels $\mathrm{C}$ and $\mathrm{F}$ ). At low potentials (panel C), the enzyme follows standard Michaelis-Menten kinetics while at higher potentials, the enzyme is inhibited by excess of nitrate (the red trace are fits in both cases). The figure is reproduced with permission from [26]. Copyright 2010 American Chemical Society. 
the ones used for studying $\mathrm{NiFe}$ hydrogenases, it was possible to determine the complete dependency of the rate constants on the potential, compatible with the presence of three redox states for both the active and inactive species. This is consistent with what we expect from the chemistry of the catalytic cycle, in which the molybdenum active site cycles between the (VI) and (IV) states[31].

The values of the rate constants and their dependence on potential and substrate concentration were used to compute the fraction of the enzyme in a nitrate-inhibited state as a function of potential and nitrate concentration, and to deduce the fraction of this inhibited state that is paramagnetic. It was concluded that the paramagnetic inactive species never accounts for more than about $10 \%$ of the total sample[31].

\subsection{Inactivation of copper nitrite reductase}

The copper nitrite reductase (NiR) from Alcaligenes faecalis reduces nitrite to nitric oxide at copper active sites. Protein film voltammetry revealed that NiR inactivates slowly and reversibly under reductive conditions[55]. Cyclic voltammograms showed a lower catalytic current in the scan starting at negative potential, indicating reductive inactivation, and chronoamperometry experiments allowed the determination of the rates of interconversion between the active and inactive forms and their dependence on nitrite concentration. The observed rates of inactivation decrease at high concentrations of nitrite and confirmed the existence of an equilibrium between an active reduced conformer that binds the substrate and an inactive reduced state (IRS) that does not [56, 55]. The activation rate of prereduced $\mathrm{NiR}$ was found to be small $\left(\approx 0.1 \mathrm{~s}^{-1}\right)$, independent of potential in the range of $-200 \mathrm{mV}$ to $+100 \mathrm{mV}$ vs SHE, and approximately equal to the inactivation rate (in the absence of nitrite, the amount of active and inactive reduced states is very similar). It has been proposed that the IRS observed [55] likely corresponds to the three-coordinated reduced $\mathrm{Cu}$ site incapable of binding nitrite or other ligands revealed by EXAFS and X-ray crystallography [57-61].

\subsection{Redox state-dependent inhibition of bilirubin oxydases/laccases by halides}

Bilirubin oxidases are multi-copper oxidase (MCO) enzymes capable of coupling the oxidation of bilirubin to the reduction of oxygen to water. As other MCOs, they contain $4 \mathrm{Cu}$ ions: one type 1 (T1), one type 2 (T2) located in a trinuclear center (TNC), and two type 3 (T3) interconnected with T2 and that complete the TNC. Electrochemical and spectroscopic techniques have allowed the identification of different resting species of MCOs, in particular a fully oxidised resting form (RO) [62] and a partly oxidised form called alternative resting form (AR) [63]. Since MCOs are of great interest for bioelectrochemical applications - they are used in biosensors and as biocatalysts in fuel cells-, the inhibition of $\mathrm{O}_{2}$ reduction by chloride of bilirubin oxidases has been investigated, particularly as a function of potential and $\mathrm{pH}[27]$.

Cyclic voltammograms of $\mathrm{O}_{2}$ reduction by bilirubin oxidase from Bacillus pumilus (figure 1e) show a pronounced hysteresis in the presence of chloride: in the forward scan to low potential, $\mathrm{O}_{2}$ reduction is observed at a lower potential than in the absence of the inhibitor, and in the reverse scan, the catalytic reaction is less affected by chloride because of the exposure of the enzyme to reducing potentials. It was concluded that the active form in the absence of chloride derives from the $\mathrm{RO}$ form and, upon addition 
of the inhibitor, this species is converted to the AR form, in which one of the $\mathrm{Cu}$ in T3 $(\mathrm{T} 3 \beta)$ is oxidised while the TNC Cu atoms are reduced, and a reductive step is required for $\mathrm{O}_{2}$ reduction. Further voltammetric and chronoamperometric studies confirmed that the formation of AR requires the presence of both chloride and oxidative conditions, so that $\mathrm{T} 3 \beta \mathrm{Cu}$ is oxidised. The kinetics of $\mathrm{AR}$ formation depend on $\mathrm{pH}$ : the inhibition is faster at low $\mathrm{pH}$ in the presence of $\mathrm{NaCl}$. Chloride inhibition is reversible and the reactivation rate of the $\mathrm{AR}$ form depends on the value of the reductive potential: it is faster at more negative potentials[27]. The RO/AR interconversion in the presence of $\mathrm{NaCl}$ was also found in laccases [64], which belong to the MCOs family as well, and bilirrubin oxidases from both prokariotes and eukariotes [65].

\subsection{Horseradish peroxidase}

The horseradish peroxidase (HRP) is a heme enzyme that catalyzes the reduction of $\mathrm{H}_{2} \mathrm{O}_{2}$ into water. This enzyme is extremely popular for use in biosensors, since it allows easy electrochemical detection of substrates who are processed by enzymes generating $\mathrm{H}_{2} \mathrm{O}_{2}$. Under high concentrations of $\mathrm{H}_{2} \mathrm{O}_{2}$, HRP can form an oxidized deadend state called the oxyperoxidase form of the enzyme, which can reenter the catalytic cycle either by slowly giving back the free form of the enzyme or by being reduced into an intermediate of the catalytic cycle. This slow, oxidative inactivation gives raise to hysteresis visible in cyclic voltammograms, and was studied and modelled in detail by Dequaire and coworkers[66].

\section{Reversible inactivations with 2 inactive species}

There are many examples of cases in which the inactivation processes observed in cyclic voltammetry are biphasic or multiphasic, rather than monophasic, which shows the existence of two (or more) inactive species. There are two distinct possibilities to arrange two inactive species, depending on whether the inactive species $I_{1}$ and $I_{2}$ are formed in parallel (eq (11)) or sequentially (eq. (12)).

$$
\begin{aligned}
& \mathrm{I}_{1} \underset{k_{i}^{\prime}}{\stackrel{k_{a}^{\prime}}{\rightleftharpoons}} \mathrm{A} \underset{k_{a}^{\prime \prime}}{\stackrel{k_{i}^{\prime \prime}}{\rightleftharpoons}} \mathrm{I}_{2} \\
& \mathrm{~A} \underset{k_{a}^{\prime}}{\stackrel{k_{i}^{\prime}}{\rightleftharpoons}} \mathrm{I}_{1} \underset{k_{a}^{\prime \prime}}{\stackrel{k_{i}^{\prime \prime}}{\rightleftharpoons}} \mathrm{I}_{2}
\end{aligned}
$$

Both models give a time dependence of the fraction of active species that can be put under the following form:

$$
a(t)=a_{+} \exp \left(-\frac{t-t_{0}}{\tau_{+}}\right)+a_{-} \exp \left(-\frac{t-t_{0}}{\tau_{-}}\right)+a_{\infty}
$$

The expressions of $a_{+}, a_{-}, \tau_{+}$and $\tau_{-}$as a function of the rates and the initial concentrations depend on the scheme, and are given in supplementary section S2. 
Experimental strategy. Like for the case of monophasic inactivations, a strategy using a sequence of steps at different potentials is the best approach to elucidate the kinetics. For improving the accuracy, it is better to use a more complex sequence of steps that includes several steps at the same potential but with different durations (see ref. 67 for examples of potential step experiments).

Sequential versus parallel. Schemes (11) and (12) are truly indistinguishable when only one step is considered. We propose in supplementary section S3 formulas that convert the microscopic rate constants between the "parallel" and the "sequential" model so that both give the same time dependence (the parameters of equation (13)) given an initial active fraction of 1. Further computations suggest that sequences of alternating steps could open the possibility to discriminate between the two models, but, in practice, the differences are so subtle that discrimination is not possible.

Back on the meaning of "kinetic species". Looking at equation (13), one can give a more specific meaning to the definition of "kinetic species". If one of the time constants is either much faster or much slower than what can be detected on the time scale of the experiment, then the corresponding phase is simply not detected, giving a monophasic response. Depending on the limiting case involved (and the scheme at play), it may be that $I_{1}$ or $I_{2}$ never forms, or, that $I_{1}$ and $I_{2}$ interconvert too fast to be distinguished, transforming them effectively into a single species. Alternatively, the kinetics of formation of the inactive species may be too similar to be distinguished, in which case a model with one inactive species may fit equally well.

\subsection{Oxidative inhibition of FeFe hydrogenases}

By far the most studied example of reversible biphasic inactivation is that of the FeFe hydrogenases. It has long been observed that, as in NiFe hydrogenases, cyclic voltammograms of $\mathrm{FeFe}$ hydrogenases show a pronounced hysteresis at high potentials consistent with a slow, reversible, oxidative, inactivation process (see figure 1f). This was first observed with the FeFe hydrogenase from Desulfovibrio desulfuricans, and was attributed to the regeneration of the state called HoxInact[68], which correspond to a stable, $\mathrm{O}_{2}$-insensitive state[12]. However, this attribution was questioned by the fact that this inactivation is also visible for other FeFe hydrogenases, like that of Chlamydomonas reinhardtii or Clostridium acetobutylicum, for which the HoxInact state was never observed. It was recently shown that generating the HoxInact state seems to require sulfide[69], which is in general absent from electrochemical buffers.

Using series of potential steps, it was possible to show that the inactivation process is biphasic, and determine the rates constants (assuming a parallel process). The dependence on potential and $\mathrm{pH}$ suggested that, prior to reactivation, the inactive species must take a proton and an electron (figure 5). The inactivation rate constants showed a surprising linear dependence on the pressure of $\mathrm{H}_{2}$, which was initially interpreted as the inhibition being triggered by the binding of $\mathrm{H}_{2}$ to minor isomers of the active site, leading to the formation of unreactive hydrides[67].

However, further investigation showed that the inactivation is also strictly dependent on the presence of chloride (or bromide), which prompted a complete reinvestigation of the process. By looking at the $K_{m}$ for $\mathrm{H}_{2}$ under various concentrations of 

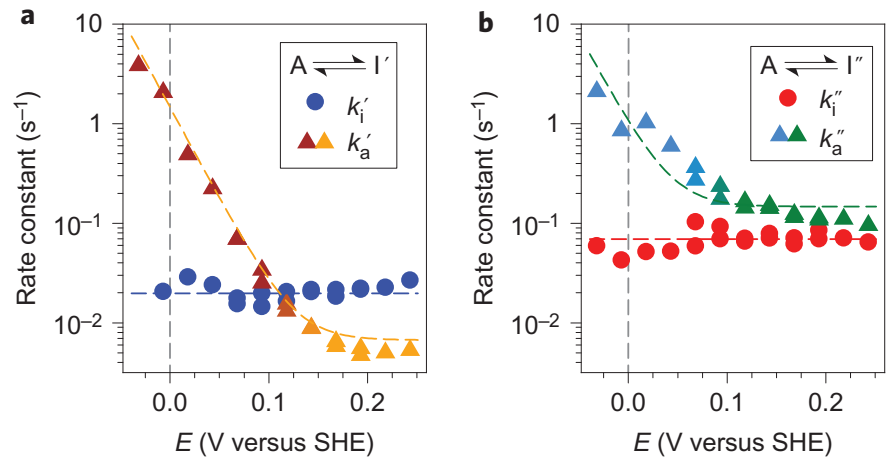

Figure 5: Inactivation (circles) and reactivation (triangles) rate constants for the formation of the two inactive species of the $\mathrm{FeFe}$ hydrogenase from Chlamydomonas reinhardtii.

chloride and at different potentials, it was shown that, under oxidizing conditions, the $K_{m}$ decreases upon increasing the concentration of chloride, consistent with it being an uncompetitive inhibitor, i.e. an inhibitor that binds to an intermediate of the catalytic cycle, and hence requires the substrate to bind first, which explains the linear dependence of the inactivation constant on $\mathrm{H}_{2}[70]$.

Independently of the understanding of the inactivation process, the characterization of the anaerobic inactivation was necessary for the study of the reaction of FeFe hydrogenase with $\mathrm{O}_{2}$ (aerobic inactivation). Indeed, the study has to be performed in oxidizing conditions to prevent the direct reduction of $\mathrm{O}_{2}$ at the electrode, and consequently this implies the formation of anaerobic inactive states, which are protected from $\mathrm{O}_{2}$ [67]. Taking this effect into account was necessary to deconvolve the anaerobic inactivation process from the aerobic one[28], yielding useable data for the complete study of the aerobic inactivation[71].

\section{Irreversible (in)activations}

The above sections have dealt with reversible inactivations, which are by far the easiest to study, because, as was pointed out above, the final results of a potential step do not depend on the history of the sample, just on the values of the activation/inactivation rates, which makes it possible to repeat the experiments with a given protein film, accumulate data and improve reliability. On the other hand, irreversible processes happen by definition just once, and require the making of a new film for every single experiment, which is far more troublesome.

Irreversible inactivations. It is very difficult to study irreversible inactivations, because they are essentially undistinguishable from film loss. They sometimes can be studied if they are related to other, reversible processes, and display a strong dependence on, e.g., potential. One example of this is the study of the irreversible loss during the course of the reversible oxidative inactivation of $\mathrm{FeFe}$ hydrogenases. By plotting the irreversible loss rate constant as a function of the steady-state active fraction, it was possible to show that the irreversible inactivation mostly comes from the slow oxidation of the 
active species[67]. However, in general, the non-reproducibility of film loss makes it very challenging to detect the patterns in the irreversible loss of catalytic current that could be attributed to chemical reactions.

\subsection{Reductive activation of periplasmic nitrate reductase}

On the contrary, irreversible activations are easier to study, because there can be no ambiguity concerning their nature: if the magnitude of the current increases over time, it necessarily means that the enzyme activates.

One of the first examples of an irreversible reductive activation comes from the molybdoenzyme nitrate reductase NarGH from Paracoccus pantotrophus. For some preparations, it was observed that the first voltammogram recorded with a film display a very pronounced hysteresis that is absent from subsquent ones (figure $1 \mathrm{~g}$ ), reflecting an activation that occurs only the first time the enzyme is reduced[29]. This phenomenon is in fact common for molybdenum enzymes, having been observed on other nitrate reductases like Synechococcus elongatus NarB[29], Rhodobacter sphaeroides NapAB [72, 73], E. coli NarGH[74], but also in the case of formate dehydrogenase[75].

Reductive activations are also very common in the case of NiFe hydrogenases, for which the so-called $\mathrm{NiA}$ and $\mathrm{NiB}$ oxidized inactive states activate during exposures to reducing conditions, which can be followed using electrochemical techniques[25, 76, 77, 37].

One of the examples of better studied irreversible activation is that of the periplasmic nitrate reductase NapAB from Rhodobacter sphaeroides. It was observed that the first time the enzyme is reduced in the presence of substrate, e.g. with cyclic voltammograms, the activity slowly increases. This activation process is independent of the presence of substrate, but of course, its kinetics can only be determined in its presence so that the evolution of the activity over time can be monitored.

The rate of activation was determined as a function of the electrode potential, showing a sigmoidal dependence, with a plateau at low potentials, and an exponential decrease for high potentials. This dependence suggest that a reduction step at equilibrium is involved in the activation process.

The activation amplitude correlated with the fraction of the enzyme initially in the so-called $\mathrm{Mo}(\mathrm{V})$ "high $g$ resting" EPR signature. The irreversible nature of the activation led to postulate that the signature would vanish slowly but irreversibly at relatively high potentials. This was confirmed by following the time evolution of the EPR spectrum of a sample under controlled, mildly reducing conditions. Hence, the reductive first activation correspond to the irreversible disappearance of the species giving rise to the $\mathrm{Mo}(\mathrm{V})$ "high $g$ resting" signature.

Further work using advanced EPR techniques showed subtle changes in the electronic coupling between the Mo center and the nearby FeS cluster between the "inactive" and the "activated" state, but no drastic change in the coordination sphere, suggesting that the activation is not in the coordination sphere of the Mo center, but more remote, and pointed towards the possible involvement of the pterin cofactor[73].

\subsection{Reductive activation of respiratory nitrate reductase}

A similar process also occurs with the respiratory nitrate reductases, as was first evidenced with Paracoccus pantotrophus NarGH[29] (figure 1g). This behaviour was 
later observed with E. coli NarGH samples, and studied using chronoamperometry[74]. It was shown that the activation is biphasic. Similarly to the reversible inactivation, there are two ways to arrange the inactive species, that are reactivated either in parallel (scheme (14)) or sequentially (scheme (15)).

$$
\begin{aligned}
& \mathrm{I}_{1} \longrightarrow \mathrm{A} \longleftarrow \mathrm{I}_{2} \\
& \mathrm{I}_{1} \rightleftharpoons \mathrm{I}_{2} \longrightarrow \mathrm{A}
\end{aligned}
$$

The irreversible nature of the activation induces constraints that are absent from the reversible case, and which makes the discrimination a lot easier. In the case of an irreversible activation in parallel, the amplitude of the two phases are proportional to the initial concentrations of the inactive species (this is false for the reversible activations), so that the activation can only be parallel (scheme (14)) if the amplitude of the diverse phases are independent of the conditions of the activations (which should not influence the initial state).

This observation was used to prove that the activation mechanism in the case of $E$. coli $\mathrm{NarGH}$ is sequential (eq. (15)), since the amplitudes of the two phases strongly depends on potential. A global fitting strategy was used to model the experimental data at different potentials, by assuming that in scheme (15), the first step is potentialindependent, and thus its rate constants are common to all the activations at different potentials, while that of the second step is assumed to depend on potential; this approach provided very satisfactory fits, showing that this scheme is enough to reproduce the experimental data[74].

The study went on to look for spectroscopic signatures of the initially inactive states, but no correlations between the fractions of initially inactive enzymes and any of the spectroscopic signatures observed on the enzyme could be found, unlike in the case of NapAB[74].

\section{When inactive species are not fully inactive...}

In all the studies described above, the "inactive" species have truly lost all of their activity. This often makes sense in chemical terms, when thinking about inactive states whose spectroscopic signatures or crystallographic structures reveal the presence of a ligand (hydroxo in the case of the NiFe hydrogenase, for instance) in the place where the substrate binds, simply preventing catalysis. This also greatly simplifies data analysis, because it allows the complete determination of the inactivation/reactivation rates.

The cases where the "inactive state" is in fact "less active", or "differently active" are much less common, perhaps because they are harder to identify. In chemical terms, this points towards subtle modifications of the active site, probably in the second coordination sphere or even further, so that the effect on the chemistry is not drastic enough as to shut down catalysis, but strong enough to affect its kinetics. There are not many examples of such inactive species in the literature, but the FeFe hydrogenases display such behaviour. We have seen above that they inactivate by the uncompetitive binding of halides under oxidizing conditions. They are also subject to a loss of activity under very reducing conditions, which is evidenced by a large slow loss of proton reduction activity in chronoamperometry. However, this loss of proton reduction activity is not 
mirrored by an equal loss of the $\mathrm{H}_{2}$ oxidation activity, which seems much less affected. Using an approach combining cyclic voltammograms, to record the wave shape, and high potential chronoamperometry experiments to follow the reactivation process, it was possible to evidence a change in the shape of the cyclic voltammograms. This was interpreted by assuming that the inactivation forms an alternative form that has lost all its proton reduction capacity, but hardly any of its $\mathrm{H}_{2}$ oxidation, which slowly converts back to the "usual" active form upon oxidation[30].

This observation raises many questions, first with respect to the chemistry: what kind of reversible changes can occur in the vicinity of the FeFe hydrogenase's active site that would selectively shut down proton reduction but hardly affect $\mathrm{H}_{2}$ oxidation? And, more generally, is that an isolated example, or is the phenomenon in fact very common for metalloenzymes, but unnoticed because of the lack of appropriate tools to detect it? In that respect, it should be emphasized that the changes in the $\mathrm{H}_{2}$ oxidation ability are too small to be noticeable in solution assays (15\% or less).

\section{General discussions}

Slow redox (in)activation processes have been observed using Protein Film Voltammetry in many metalloenzymes harboring a large variety of metals ( $\mathrm{Ni}, \mathrm{Fe}, \mathrm{Cu}, \mathrm{Mo} . .$. in their active sites. In fact, a significant fraction of the metalloenzymes studied by PFV was shown to undergo slow redox-driven inactivations, which suggest that these phenomena may be more common than is currently believed, since they are usually very hard to observe using traditional enzymatic assays. As an example, it was possible to show the existence of redox-dependent substrate inhibition in the case of $R$. sphaeroides NapAB using high potential electron donors[26], but the assay traces do not permit to resolve the temporal evolution of the activity, which effectively prevents the study of the process.

These redox-driven inactivation processes are not restricted to redox enzymes, but they also occur in the case of molecular catalysts that attempt to copy their reactivity. An example comes from the family of the so-called DuBois nickel-diphosphine catalysts, whose ligands acting as proton relays can be protonated in an endo or exo conformation, and become temporary "locked" when the protonation occurs in the exo conformation[78, 79]. Another example is the occurrence of "odd" voltammetric traces suggestive of redox (in)activation processes in the case of a rhodium complex which catalyzes the oxidation of glucose[80]. There are undoubtedly more occurrences of these behaviours with metallic complexes, but this may have been overlooked, since these complexes are generally studied less extensively than the enzymes whose functionality they attempt to copy.

Heterogeneous catalysts also show complex (in)activation behaviours. One can for instance cite spectroelectrochemical methods which were used to identify adsorbed species on the heterogeneous catalyst $\mathrm{Pt}$ [81], which is inactivated by $\mathrm{CO}$ at high potential during ethanol oxidation. Electrochemistry was also combined with surfaceenhanced infrared absorption spectroscopy (ATR-SEIRAS) in the study of the mechanism of electrocatalytic oxidation of formic acid on $\mathrm{Pd}$. The reaction is deactivated or reactivated when the surface of the catalyst is oxidised or reduced[82]. 
The most informative way to study these (in)activation processes is to determine the full dependence of the (in)activation rate constants on the electrode potential, and then see how the other parameters (substrate concentration, $\mathrm{pH}$, etc...) affect these curves. Without a priori knowledge of the process, the only way to determine the rate constants is to use series of potential steps. The steps should include three potentials, one used at the beginning to put the enzyme in a fully active state, and then two other potentials where the enzyme will inactivate and reactivate (one "higher", one "lower"). The full dependence on potential is obtained by repeating potential steps experiments changing the two latter potentials. Several aspects should be taken into account when planning the experiments: (i) the "higher" and "lower" potentials should be chosen so as to obtain large, visible, inactivations and reactivations, since low amplitude data yields very unreliable rate constants. (ii) the experiments should be repeated so that the "higher" potential of some experiments is, as many times as possible, the "lower" one of others: checking that the same values are obtained regardless of whether the rates are determined from a "higher" step or a "lower" step is a good self-consistency check. For instance, looking at the potential profile of figure 2, the two potentials are $-65 \mathrm{mV}$ ("lower") and $60 \mathrm{mV}$ ("higher"), so that other experiments should be run with $60 \mathrm{mV}$ as the "lower" potential or $-65 \mathrm{mV}$ as the "higher". (iii) the difference in potential between the steps should not be too high to minimize the capacitive current of the electrode, whose subtraction is necessary for fitting. The strategies that have been used so far relied on a constant difference between the two potentials, but this may not necessarily be applicable to all processes.

Looking at equations (4), it is clear that when the ratio $k_{i} / k_{a}$ tends to very low or very high values, the lesser of the two rate constants is very hard to determine experimentally, since small inaccuracies in the determination of the asymptotic values $\left(a_{\infty}\right)$ of the currents will results in large variations in the lesser rate. Experimentally, it is hard to reliably measure ratios much above 30 (or below 1/30). While equation (4) applies to monophasic relaxations, the above conclusions also extend to the multiphasic case.

The dependence on potential of the rate constants informs on the redox states of the species that react: the activation rate constants inform on the inactive state, and conversely, the inactivation rate constants on the species part of the catalytic cycle. It is interesting to remark that, for the case of both $\mathrm{NiFe}$ and FeFe hydrogenases, the dependence of the (in)activation rate constants is the same: the inactivation rate constant is independent of potential while the activation rate constant decreases exponentially with the potential, reaching a constant minimum at high potentials (equations (9)).

It is remarkable that the inactivation rate constants for all hydrogenases are independent of potential. Not only does this mean that the inactivation is rate-limited by a purely chemical step, but also that the species that inactivates has a steady-state concentration in the catalytic cycle that does not depend on potential. This can be interpreted by assuming that the species that inactivates is the most oxidized "resting state" of the catalytic cycle, i.e. the state which accumulates in the absence of substrate. This interpretation is plausible in the case of the NiFe hydrogenases: the state that inactivates could be the Ni-SIa. However, this interpretation does not hold in the case of FeFe hydrogenases, for which the inactivation occurs from a state in the catalytic cycle after the binding of $\mathrm{H}_{2}$ [70], which implies that this state has a concentration that does not depend on potential, at least for the potential range in which the inactivation rate con- 
stants can be determined reliably, suggesting that the steps that follow this state is not an oxidation, but probably more a pure chemical step.

The inactivation rate constants are not necessarily independent of potential, and, in the case of $R$. sphaeroides NapAB, the dependence is consistent with the existence of three distinct redox states of the catalytic cycle. However, the inactivation rate constants were not determined with sufficient precision to provide reliable data on the redox states of the catalytic cycle[31].

Although, as was shown above, the use of systematic approaches to determine the rate constants of (in)activation can already provide useful information on the nature of the steps involved in the inactivation process and on the chemical composition of the inactive species, it is desirable to combine the electrochemical investigation with other approaches, such as DFT[67, 71], or when that is feasible, with spectroscopic techniques. We have already discussed the relationship between spectroscopic signatures and activation processes above in the case of the disappearance of the $\mathrm{Mo}(\mathrm{V})$ "high $g$ resting" signal of $\mathrm{NapAB}$, in which the parallel was made between the electrochemical experiments and solution experiments[72]. We now discuss cases in which the spectroscopic experiments are conducted either simultaneously with the electrochemical experiments, or in spectroelectrochemical cells in conditions similar to PFV experiments. The case of $\mathrm{NiFe}$ hydrogenases is a perfect example, with studies that were first done by combining the results of electrochemical investigation with classical spectroelectrochemical titrations [83], or, more recently, taking advantage of the simultaneous detection of IR spectra and the measurement of catalytic current afforded by surfaceenhanced IR[84], or the use of volumic electrodes[85, 86] to relate the (in)activation process with the appearance of specific signatures. It is also worth mention the work of Lockwood and coworkers on the bacterial cytochrome $c$ nitrite reductase. They investigated the inhibition of hydroxilamine reduction by nitrite in a mutant of the active site, and were able to demonstrate that the binding of nitrite occurs to specific redox states of the active heme[87]. In all the cases, the concomitant detection of the (in)activation processes by electrochemistry with the (dis)appearance of specific allow the understanding of the chemical transformations underlying the inactivation, and help

discriminating between spectroscopic signatures that may inform on the catalytic cycle and those that relate to inactive species.

\section{Conclusion}

Redox (in)activations are prevalent in the world of redox metalloenzymes, and possibly more common among man-made catalysts that attempt to copy their reactivity than is currently thought. We have given keys above to study these processes and interpret the resulting rates, showing that these give insights on the metalloenzymes. We hope that this review will provide the basis for extending the studies of other (in)activation processes.

\section{Acknowledgments}

This work was funded by the French national research agency (grant numbers ANR14-CE05-0010 and ANR-17-CE11-0027), the A*Midex foundation of Aix-Marseille 
University (grant number ANR-11-IDEX-0001-02). The authors are part of the French Bioinorganic Chemistry group (http://frenchbic.cnrs.fr).

\section{Author biographies}

Melisa del Barrio obtained her Ph.D. from the University of Zaragoza in 2014. She held postdoctoral positions in Toulouse and then Marseille, with Christophe Léger and Vincent Fourmond, where she focused her research on kinetic studies of hydrogenases. Her interests also include the development of nanostructured enzymatic electrodes and biosensors.

Vincent Fourmond obtained his Ph.D. at the interface of physics and biology from Université Paris Diderot in 2007. He held postdoctoral positions first in the group of Christophe Léger in Marseille and then Vincent Artero in Grenoble, before coming back to Marseille as a permanent CNRS researcher in 2011. His research interests revolve around the use of kinetic techniques, principally protein film voltammetry, to understand metalloenzymes (hydrogenases, CO dehydrogenases, molybdenum enzymes), the development of methodological aspects of PFV, and the writing of the open source data analysis software QSoas[88].

\section{References}

\section{References}

[1] H. Beinert. Science, 1997, 277, 653-659.

[2] D. W. Bak and S. J. Elliott. Curr. Opin. Chem. Biol., 2014, 19, 50-58.

[3] A. M. Koval, B. R. Jagger, and R. A. Wheeler. ChemPhysChem, 2017, 18 (1), 39-41.

[4] D. J. Ferraro, L. Gakhar, and S. Ramaswamy. Biochem. Biophys. Res. Commun., 2005, 338 (1), 175-190.

[5] J. L. H. Busch, J. L. Breton, B. M. Bartlett, F. A. Armstrong, R. James, and A. J. Thomson. Biochem. J., 1997, 323, 95-102.

[6] M. G. G. Fuchs, F. Meyer, and U. Ryde. J. Biol. Inorg. Chem., 2010, 15 (2), 203-212.

[7] A. Schiffer, K. Parey, E. Warkentin, K. Diederichs, H. Huber, K. O. Stetter, P. M. H. Kroneck, and U. Ermler. J. Mol. Biol., 2008, 379 (5), 1063-1074.

[8] M. M. Werst, M. C. Kennedy, A. L. P. Houseman, H. Beinert, and B. M. Hoffman. Biochemistry, 2002, 29, 10533-10540.

[9] F. Forouhar, S. Arragain, M. Atta, S. Gambarelli, J.-M. Mouesca, M. Hussain, R. Xiao, S. Kieffer-Jaquinod, J. Seetharaman, T. B. Acton, G. T. Montelione, E. Mulliez, J. F. Hunt, and M. Fontecave. Nat. Chem. Biol., 2013, 9 (5), 333-338. 
[10] E. Mulliez, V. Duarte, S. Arragain, M. Fontecave, and M. Atta. Front. Chem., 2017, 5, 17.

[11] A. J. Pierik, W. R. Hagen, J. S. Redeker, R. B. G. Wolbert, M. Boersma, M. F. J. M. Verhagen, H. J. Grande, C. Veeger, P. H. A. Mutsaers, R. H. Sands, and W. R. Dunham. Eur. J. Biochem., 1992, 209 (1), 63-72.

[12] C. v. Dijk, A. v. Berkel-Arts, and C. Veeger. FEBS Lett., 1983, 156 (2), 340-344.

[13] S. Morra, M. Arizzi, F. Valetti, and G. Gilardi. Biochemistry, 2016, 55 (42), 5897-5900.

[14] A. Cornish-Bowden. Fundamentals of Enzyme Kinetics. Portland Press, 3rd edition, 2004. ISBN 1855781581.

[15] C. Léger and P. Bertrand. Chem. Rev., 2008, 108 (7), 2379-2438.

[16] F. A. Armstrong, H. A. Heering, and J. Hirst. Chem. Soc. Rev., 1997, 26, 169-179.

[17] F. A. Armstrong, N. A. Belsey, J. A. Cracknell, G. Goldet, A. Parkin, E. Reisner, K. A. Vincent, and A. F. Wait. Chem. Soc. Rev., 2009, 38 (1), 36-51.

[18] V. Fourmond and C. Léger. Adv. Biochem. Eng. Biotechnol., 2016, 158, 1-41.

[19] A. F. Wait, C. Brandmayr, S. T. Stripp, C. Cavazza, J. C. Fontecilla-Camps, T. Happe, and F. A. Armstrong. J. Am. Chem. Soc., 2011, 133 (5), 1282-1285.

[20] M. Sensi, C. Baffert, L. Fradale, C. Gauquelin, P. Soucaille, I. Meynial-Salles, H. Bottin, L. de Gioia, M. Bruschi, V. Fourmond, C. Léger, and L. Bertini. ACS Catal., 2017, 7, 7378-7387.

[21] C. Baffert, L. Bertini, T. Lautier, C. Greco, K. Sybirna, P. Ezanno, E. Etienne, P. Soucaille, P. Bertrand, H. Bottin, I. Meynial-Salles, L. de Gioia, and C. Léger. J. Am. Chem. Soc., 2011, 133 (7), 2096-2099.

[22] C. Léger, S. Dementin, P. Bertrand, M. Rousset, and B. Guigliarelli. J. Am. Chem. Soc., 2004, 126 (38), 12162-72.

[23] V. Fourmond, T. Lautier, C. Baffert, F. Leroux, P.-P. Liebgott, S. Dementin, M. Rousset, P. Arnoux, D. Pignol, I. Meynial-Salles, P. Soucaille, P. Bertrand, and C. Léger. Anal. Chem., 2009, 81 (8), 2962-2968.

[24] V. Fourmond, P. Infossi, M.-T. Giudici-Orticoni, P. Bertrand, and C. Léger. J. Am. Chem. Soc., 2010, 132 (13), 4848-4857.

[25] A. Jones, S. Lamle, H. Pershad, K. Vincent, S. Albracht, and F. Armstrong. J. Am. Chem. Soc., 2003, 125 (28), 8505-8514.

[26] V. Fourmond, M. Sabaty, P. Arnoux, P. Bertrand, D. Pignol, and C. Léger. J. Phys. Chem. B, 2010, 114 (9), 3341-3347. 
[27] A. de Poulpiquet, C. H. Kjaergaard, J. Rouhana, I. Mazurenko, P. Infossi, S. Gounel, R. Gadiou, M. T. Giudici-Orticoni, E. I. Solomon, N. Mano, and E. Lojou. ACS Catal., 2017, 7 (6), 3916-3923.

[28] C. Orain, L. Saujet, C. Gauquelin, P. Soucaille, I. Meynial-Salles, C. Baffert, V. Fourmond, H. Bottin, and C. Léger. J. Am. Chem. Soc., 2015, 137 (39), 1258012587.

[29] S. J. Field, N. P. Thornton, L. J. Anderson, A. J. Gates, A. Reilly, B. J. N. Jepson, D. J. Richardson, S. J. George, M. R. Cheesman, and J. N. Butt. Dalton Trans., 2005, (21), 3580-3586.

[30] V. Hajj, C. Baffert, K. Sybirna, I. Meynial-Salles, P. Soucaille, H. Bottin, V. Fourmond, and C. Léger. Energy Environ. Sci., 2014, 7 (2), 715-719.

[31] J. G. Jacques, B. Burlat, P. Arnoux, M. Sabaty, B. Guigliarelli, C. Léger, D. Pignol, and V. Fourmond. Biochim. Biophys. Acta, 2014, 1837 (10), 1801-1809.

[32] M. Teixeira, I. Moura, A. V. Xavier, B. H. Huynh, D. V. DerVartanian, H. D. Peck, J. LeGall, and J. J. Moura. J. Biol. Chem., 1985, 260 (15), 8942-8950.

[33] V. M. Fernandez, E. Hatchikian, and R. Cammack. Biochim. Biophys. Acta, 1985, $832(1), 69-79$.

[34] T. Goris, A. F. Wait, M. Saggu, J. Fritsch, N. Heidary, M. Stein, I. Zebger, F. Lendzian, F. A. Armstrong, B. Friedrich, and O. Lenz. Nat. Chem. Biol., 2011, 7 (5), 310-318.

[35] A. L. de Lacey, E. C. Hatchikian, A. Volbeda, M. Frey, J. C. Fontecilla-Camps, and V. M. Fernandez. J. Am. Chem. Soc., 1997, 119 (31), 7181-7189.

[36] Y. Shomura, K.-S. Yoon, H. Nishihara, and Y. Higuchi. Nature, 2011, 479 (7372), 253-256.

[37] A. Abou Hamdan, B. Burlat, O. Gutiérrez-Sanz, P.-P. Liebgott, C. Baffert, A. L. De Lacey, M. Rousset, B. Guigliarelli, C. Léger, and S. Dementin. Nat. Chem. Biol., 2013, 9 (1), 15-17.

[38] W. Lubitz, H. Ogata, O. Rüdiger, and E. Reijerse. Chem. Rev., 2014, 114 (8), $4081-4148$

[39] V. Fernandez, R. Aguirre, and E. Hatchikian. Biochim. Biophys. Acta, 1984, $790(1), 1-7$.

[40] R. Mege and C. Bourdillon. J. Biol. Chem., 1985, 260 (27), 14701-6.

[41] B. Limoges and J.-M. Saveant. J. Electroanal. Chem., 2004, 562 (1), 43-52.

[42] C. Léger, A. K. Jones, S. P. J. Albracht, and F. A. Armstrong. J. Phys. Chem. B, 2002, 106 (50), 13058-13063. 
[43] V. Fourmond, C. Baffert, K. Sybirna, T. Lautier, A. Abou Hamdan, S. Dementin, P. Soucaille, I. Meynial-Salles, H. Bottin, and C. Léger. J. Am. Chem. Soc., 2013, 135 (10), 3926-3938.

[44] A. Abou Hamdan, P.-P. Liebgott, V. Fourmond, O. Gutiérrez-Sanz, A. L. De Lacey, P. Infossi, M. Rousset, S. Dementin, and C. Léger. Proc. Natl. Acad. Sci. U.S.A., 2012, 109 (49), 19916-19921.

[45] P. Ceccaldi, M. C. Marques, V. Fourmond, I. C. Pereira, and C. Leger. Chem. Commun., 2015, 51 (75), 14223-14226.

[46] A. Ciaccafava, P. Infossi, M. Ilbert, M. Guiral, S. Lecomte, M. T. GiudiciOrticoni, and E. Lojou. Angew. Chem. Int. Ed. Engl., 2012, 51 (4), 953-956.

[47] V. Radu, S. Frielingsdorf, S. D. Evans, O. Lenz, and L. J. C. Jeuken. J. Am. Chem. Soc., 2014, 136 (24), 8512-8515.

[48] N. Plumeré, O. Rüdiger, A. A. Oughli, R. Williams, J. Vivekananthan, S. Pöller, W. Schuhmann, and W. Lubitz. Nat. Chem., 2014, 6 (9), 822-827.

[49] P. Arnoux, M. Sabaty, J. Alric, B. Frangioni, B. Guigliarelli, J.-M. Adriano, and D. Pignol. Nat. Struct. Mol. Biol., 2003, 10 (11), 928-934.

[50] S. Grimaldi, B. Schoepp-Cothenet, P. Ceccaldi, B. Guigliarelli, and A. Magalon. Biochim. Biophys. Acta, 2013, 1827 (8-9), 1048-1085.

[51] G. Schwarz, R. R. Mendel, and M. W. Ribbe. Nature, 2009, 460 (7257), 839-847.

[52] S. Leimkühler and C. Iobbi-Nivol. FEMS Microbiol. Rev., 2016, 40 (1), 1-18.

[53] B. Frangioni, P. Arnoux, M. Sabaty, D. Pignol, P. Bertrand, B. Guigliarelli, and C. Léger. J. Am. Chem. Soc., 2004, 126 (5), 1328-9.

[54] P. Bertrand, B. Frangioni, S. Dementin, M. Sabaty, P. Arnoux, B. Guigliarelli, D. Pignol, and C. Léger. J. Phys. Chem. B, 2007, 111 (34), 10300-10311.

[55] H. Wijma, L. Jeuken, M. Verbeet, F. Armstrong, and G. Canters. J. Am. Chem. Soc., 2007, 129 (27), 8557-8565.

[56] H. J. Wijma, L. J. C. Jeuken, M. P. Verbeet, F. A. Armstrong, and G. W. Canters. J. Biol. Chem., 2006, 281 (24), 16340-16346.

[57] R. W. Strange, L. M. Murphy, F. E. Dodd, Z. H. Abraham, R. R. Eady, B. E. Smith, and S. S. Hasnain. J. Mol. Biol., 1999, 287 (5), 1001-1009.

[58] M. E. P. Murphy, S. Turley, and E. T. Adman. J. Biol. Chem., 1997, 272, 2845528460.

[59] M. J. Boulanger and M. E. P. Murphy. Biochemistry, 2001, 40, 9132-9141.

[60] M. J. Boulanger, M. Kukimoto, M. Nishiyama, S. Horinouchi, and M. E. Murphy. J. Biol. Chem., 2000, 275 (31), 23957-23964. 
[61] K. Kataoka, H. Furusawa, K. Takagi, K. Yamaguchi, and S. Suzuki. J. Biochem. (Tokyo), 2000, 127, 345-350.

[62] J. A. Cracknell and C. F. Blanford. Chem. Sci., 2012, 3 (5), 1567-1581.

[63] A. Shimizu, J. H. Kwon, T. Sasaki, T. Satoh, N. Sakurai, T. Sakurai, S. Yamaguchi, and T. Samejima. Biochemistry, 1999, 38 (10), 3034-3042.

[64] C. H. Kjaergaard, S. M. Jones, S. Gounel, N. Mano, and E. I. Solomon. J. Am. Chem. Soc., 2015, 137 (27), 8783-8794.

[65] C. H. Kjaergaard, F. Durand, F. Tasca, M. F. Qayyum, B. Kauffmann, S. Gounel, E. Suraniti, K. O. Hodgson, B. Hedman, N. Mano, and E. I. Solomon. J. Am. Chem. Soc., 2012, 134 (12), 5548-5551.

[66] M. Dequaire, B. Limoges, J. Moiroux, and J.-M. Savéant. J. Am. Chem. Soc., 2002, 124 (2), 240-53.

[67] V. Fourmond, C. Greco, K. Sybirna, C. Baffert, P.-H. Wang, P. Ezanno, M. Montefiori, M. Bruschi, I. Meynial-Salles, P. Soucaille, J. Blumberger, H. Bottin, L. de Gioia, and C. Léger. Nat. Chem., 2014, 6 (4), 336-342.

[68] A. Parkin, C. Cavazza, J. Fontecilla-Camps, and F. Armstrong. J. Am. Chem. Soc., 2006, 128 (51), 16808-16815.

[69] P. Rodríguez-Maciá, E. J. Reijerse, M. van Gastel, S. DeBeer, W. Lubitz, O. Rüdiger, and J. A. Birrell. J. Am. Chem. Soc., 2018, 140 (30), 9346-9350.

[70] M. del Barrio, M. Sensi, L. Fradale, M. Bruschi, C. Greco, L. de Gioia, L. Bertini, V. Fourmond, and C. Léger. J. Am. Chem. Soc., 2018, 140 (16), 5485-5492.

[71] A. Kubas, C. Orain, D. De Sancho, L. Saujet, M. Sensi, C. Gauquelin, I. MeynialSalles, P. Soucaille, H. Bottin, C. Baffert, V. Fourmond, R. B. Best, J. Blumberger, and C. Léger. Nat. Chem., 2017, 9 (1), 88-95.

[72] V. Fourmond, B. Burlat, S. Dementin, P. Arnoux, M. Sabaty, S. Boiry, B. Guigliarelli, P. Bertrand, D. Pignol, and C. Léger. J. Phys. Chem. B, 2008, 112 (48), 15478-15486.

[73] J. G. Jacques, V. Fourmond, P. Arnoux, M. Sabaty, E. Etienne, S. Grosse, F. Biaso, P. Bertrand, D. Pignol, C. Léger, B. Guigliarelli, and B. Burlat. Biochim. Biophys. Acta, 2014, 1837 (2), 277-286.

[74] P. Ceccaldi, J. Rendon, C. Léger, R. Toci, B. Guigliarelli, A. Magalon, S. Grimaldi, and V. Fourmond. Biochim. Biophys. Acta, 2015, 1847 (10), 10551063.

[75] W. E. Robinson, A. Bassegoda, E. Reisner, and J. Hirst. J. Am. Chem. Soc., 2017, 139 (29), 9927-9936. 
[76] S. E. Lamle, S. P. J. Albracht, and F. A. Armstrong. J. Am. Chem. Soc., 2004, 126 (45), 14899-909.

[77] S. Lamle, S. Albracht, and F. Armstrong. J. Am. Chem. Soc., 2005, 127 (18), 6595-6604.

[78] A. Dutta, A. M. Appel, and W. J. Shaw. Nature Reviews Chemistry, 2018, 2, 244-252.

[79] E. S. Rountree and J. L. Dempsey. J. Am. Chem. Soc., 2015, 137 (41), 1337113380.

[80] K. Elouarzaki, A. Le Goff, M. Holzinger, J. Thery, and S. Cosnier. J. Am. Chem. Soc., 2012, 134 (34), 14078-14085.

[81] M. Heinen, Z. Jusys, and R. J. Behm. The Journal of Physical Chemistry C, 2010, $114,9850-9864$.

[82] H. Miyake, T. Okada, G. Samjeské, and M. Osawa. Phys. Chem. Chem. Phys., 2008, 10 (25), 3662-3669.

[83] M.-E. Pandelia, V. Fourmond, P. Tron-Infossi, E. Lojou, P. Bertrand, C. Léger, M.-T. Giudici-Orticoni, and W. Lubitz. J. Am. Chem. Soc., 2010, 132 (20), 69917004.

[84] D. Millo, P. Hildebrandt, M.-E. Pandelia, W. Lubitz, and I. Zebger. Angew. Chem. Int. Ed. Engl., 2011, 50 (11), 2632-2634.

[85] R. Hidalgo, P. A. Ash, A. J. Healy, and K. A. Vincent. Angew. Chem. Int. Ed. Engl., 2015, 54 (24), 7110-7113.

[86] R. M. Evans, P. A. Ash, S. E. Beaton, E. J. Brooke, K. A. Vincent, S. B. Carr, and F. A. Armstrong. J. Am. Chem. Soc., 2018, 140 (32), 10208-10220.

[87] C. W. J. Lockwood, B. Burlat, M. R. Cheesman, M. Kern, J. Simon, T. A. Clarke, D. J. Richardson, and J. N. Butt. J. Am. Chem. Soc., 2015, 137 (8), 3059-3068.

[88] V. Fourmond. Anal. Chem., 2016, 88 (10), 5050-5052. 